\title{
EXPLORING TENNIS COACHES' INSIGHTS IN RELATION TO THEIR TEACHING STYLES
}

\author{
Shane Pill ${ }^{1}$, Mitchell Hewitt ${ }^{2}$, Ken Edwards ${ }^{3}$ \\ School of Education Flinders University ${ }^{l}$, Adelaide, South Australia \\ Coach Education Tennis Australia2, Richmond, Australia \\ School of Health and Wellbeing University of Southern Queensland ${ }^{3}$, Australia
}

\begin{abstract}
Background. The aim of this study was to explore junior tennis coaches' insights in relation to teaching styles they employ as well as the motivations and reasons that underpin these practices.

Methods. The research consisted of implementing interviews with the 13 tennis coaches. It employed purposive or theoretical sampling. Semi-structured interviews commenced with a prearranged group of questions to permit scope in direction so that the interviewer may follow what is considered as pertinent to the interviewee. The coaches were filmed during three 30 minute sessions. Prior to the interviews, each of the coaches was requested to view a portion of their video-recorded sessions. The interview data were analysed via deductive content analysis.

Results. The results highlighted a lack of knowledge concerning the theoretical and practical application of various teaching styles required for coaching tennis to junior players. The coaches lacked self-awareness with regard to their own coaching performance and were incapable of accurately describing the reasons why they implement particular ways of coaching. Coaches used an assortment of terms to identify the way they coach and that their decision to employ certain ways of coaching did not alter as a function of the age group, skill level or ability of the players they were coaching. Observing and/or discussing aspects of coaching with a mentor as well as playing experience had a greater influence on current coaching behaviour than attending an accreditation course.

Conclusion. The finding from this study is that the personally anticipated coaching behaviour of the coach was not what they realised upon observation of their coaching.
\end{abstract}

Keywords: tennis, coaching, teaching, styles, game based.

\section{INTRODUCTION}

$\mathrm{T}$ he aim of this study was to explore the coaches' insights in relation to teaching styles they employ as well as the motivations and reasons that underpin these practices. This research responds to the requests of some that in order to comprehend the nature of coaching, research initiatives should be directed at the domain of individual coaches, and how they function within their given contexts (Potrac, Jones, $\&$ Armour, 2002). Correspondingly, research that attends to the individual interpretations of coaches' experiences, understanding and knowledge and the processes that guide their actions during practice is recommended and necessary (Harvey, Cushion \&
Massa-Gonzalez 2010; Potrac et al., 2002; Smith \& Cushion, 2006).

Coaches are fundamental to the provision of sporting experiences. Each year, numerous coaching practitioners from around the world offer players of all ages and abilities assistance and direction that serve to fulfil their sporting requirements and goals. There has been a significant expansion in coaching research (Gilbert \& Trudel, 2004) that has positioned the discipline of coaching as a valid academic field of study (Lyle, 2002). Notwithstanding lengthy investigations from numerous empirical and theoretical viewpoints (Gilbert \& Trudel, 2004), much remains unknown 
about coaching and instructional practices, positive or negative, across a range of settings and sports (Lyle, 2002; Potrac, Jones \& Cushion, 2007). Therefore, research that considers "what coaches do and why they do it, still offers much in developing our understanding about coaching" (Cushion, 2010, p. 44).

Much has been written about the various instructional practices and behaviours available for coaches to employ during coaching sessions (Lyle \& Cushion, 2010). Traditionally, the educational association between coach and player has been "largely autocratic and prescriptive in nature" (Jones, 2006, p. 43). Under these instructional conditions, the coach has been considered as the "sole source of knowledge and has been responsible for the unidirectional transmission of this information to athletes who have adopted a largely passive role in the teaching and learning process" (Jones, 2006, p. 43). The term most commonly linked to this instructional practice is direct instruction. Direct instruction implies a "highly structured, teachercentered and controlled instructional environment" (Byra, 2006, p. 452). An alternative instructional practice that invites greater player decision making in relation to the how, why and what of learning is indirect instruction. This type of instruction regards the coach as a facilitator. Within this pedagogical paradigm, the coach provides minimal to no instruction or feedback and is engaged in facilitating or guiding players to explore options and solve problems. This is achieved through techniques such as posing questions, summarising, reflecting and listening (Breed \& Spittle, 2011). Other terms such as: student-centred, implicit, inquiry and guided-discovery have been used to describe common but not identical pedagogical principles related to this instructional practice.

There exist few published accounts that have reported on how, why or indeed whether sports coaches consider pedagogical principles during coaching sessions. Mallett (2005) contends that historically there has not been "much research that has examined what approaches teachers/ coaches adopt and why" (p. 1). To the researchers' knowledge, and following a wide review, there is no published research with regard to teaching styles and tennis coaches' pedagogical practice in Australia, and perhaps internationally. Anecdotal claims in the literature have suggested that tennis practitioners prefer to highlight the development of technical skills associated with tennis prior to introducing the tactical elements of the game
(Reid, Crespo, Lay \& Berry, 2007). These authors have additionally submitted that tennis coaches favour direct instruction whereby the coach dominates the decisions regarding the how, why and what of student learning. Within the context of this research investigating Australian tennis coaches, the influence of Game Sense approach (Australian Sports Commission, 1996) as the foundation of the Australian sport 'Playing for Life Philosophy' (Australian Sports Commission, 2015) has prompted tennis coach education providers in Australia to promote and emphasise gamebased coaching that embraces increased player involvement in the learning process in their formal accreditation coaching course learner guides (Crespo \& Reid, 2009; Tennis Australia, 2010a, 2010b).

\section{METHODS}

The research consisted of implementing interviews with the 13 tennis coaches. It employed purposive or theoretical sampling. This form of sampling means that "researchers intentionally select (or recruit) participants who have experienced the central phenomenon or the key concept being explored in the study" (Creswell \& Plano Clark, 2011, p. 173). The purposeful strategy employed in this part of the study was maximal variation sampling (Creswell \& Plano Clark, 2011). This strategy stipulates how "diverse individuals are chosen who are expected to hold different perspectives on the central phenomenon" (Creswell \& Plano Clark, 2011, p. 174). The fundamental notion of this particular strategy is that if "participants purposefully chosen to be different in the first place, then their views will reflect the difference and provide a good study in which the intent is to provide a complex picture of the phenomenon" (Creswell \& Plano Clark, 2011, p. 174). The criteria for maximising difference among the tennis coaches selected for this component of the study included the following:

- Gender;

- Age;

- State or territory in Australia where they coach;

- Coaching experience (years of coaching);

- Age groups most time spent coaching;

- Levels most time spent coaching.

According to Berg and Latin (2004) it is appropriate for researchers to "use their special knowledge or expertise about some groups to 
select subjects who represent the population" (p. 32). Brandl-Bredenbeck and Kampfe (2012) suggest there are no general rules for drawing a sample size. According to Keeves and Sowden (1997) in the interest of seeking detailed reporting of interpretive data, fewer respondents are better. Therefore, 13 participants were considered an appropriate number for this part of the study. However, we acknowledge that while observing and interviewing a larger number of coaches may have provided the study with more depth and breadth, but the proposed sample size is consistent with Keeves and Sowden's (1997) recommendation and was considered appropriate by the authors to achieve the aims within the given time frame. The study received university ethics approval before the research commenced.

Semi-structured interviews commenced with a prearranged group of questions to permit scope in direction so that the interviewer may follow what is considered as pertinent to the interviewee (Freebody, 2003). This flexibility was essential because any major restrictions placed upon the participants can narrow the scope of the interview and interfere with the eliciting process (ReitmanOlson \& Biolsi, 1991).

The coaches were filmed during three 30 minute sessions with a with a Sony IC MP3 recorder. Prior to the interviews, each of the coaches was requested to view a portion of their video-recorded sessions. The coaches viewed the same number of observations for consistency. These video-recorded sessions were transferred on to a disc and provided to the coaches by the lead researcher (Author 1) prior to the interview. Although originally planned to take 30-60 minutes, the interviews (which were scheduled to suit the participants' work and leisure commitments) lasted between 80 and 100 minutes in length.

At the commencement of the interview, the researcher asked the respondents to comment on their coaching sessions about the way they coached. When posing questions about the coaching habits of the participants, the lead researcher used the term way during the interviews rather than more specific terms (e.g., methods, approaches, styles). The reasoning behind this choice of language was that it was felt that by referring to specific terms it may have influenced the participants' responses when identifying and interpreting their coaching practices, in so far that the coach may use the term inadvertently as a cue or concept the participant needed to incorporate into their response A semistructured interview protocol was used whereby six questions were used as prompts to begin discussion and the interviewer (author 1) then followed by with ancillary questions to explore lines of inquiry or to clarify discussion as it occurred. The questions were

- Could you identify or tell me what has or have been the major influences on the way you currently coach?

- After watching your three observed coaching sessions what are your thoughts with regard to the way you coached?

- Are there any additional ways of coaching tennis?

- Can you interpret and define the ways you coached during your three observed coaching lessons?

- Can you interpret and define any additional ways of coaching tennis?

Using the Nvivo 8.0 software, the interview data were analysed via deductive content analysis (Patton, 2002). Each interview was transcribed verbatim into Microsoft word rich text format by author 1. As soon as the coach's interview transcript was completed, it was re-read by author 1. This process helped the researcher to: (a) become highly familiar with each coach's interview and (b) facilitate the content analysis (Cote, Salmela, Trudel, Baria, \& Russell, 1995). The interview transcripts were analysed by author 1 based upon the procedures and techniques of grounded theory. Grounded theory is an inductive methodology for developing theory grounded in data systematically collected and analysed (Saury \& Durand, 1998). It consists of two main operations: (a) breaking down the data into meaningful units, and (b) grouping units with similar meanings into broader categories. The objective of this analysis was to organise and interpret the unstructured qualitative data obtained from the interviews with the coaches. The first step was a detailed line-by-line examination of the interview transcripts and involved highlighting sections of text into meaningful and significant excerpts. Tesch (1990) defined these "meaning units as a segment of text ... comprehensible by itself and contains one idea, episode or piece of information" (p. 116). Second, similar features between meaning units were identified. This procedure of "creating categories" (Cote et al., 1995 , p. 35) involved comparing meaning units and grouping them together to organise common 
meaning units into distinct sub-categories. A subcategory was named according to the common features that all its meaning units shared (Cote et al., 1995).

As suggested by Patton (2002) exemplar quotations were used as a representational form to present the findings. Specifically, these quotations from the coaches were presented to help illustrate the categories. To increase the validity of the analysis, the coding process was discussed at different moments with a peer familiar with, and knowledgeable about, research in coaching behaviours. To ensure the soundness of the data collection and analysis, member checking was employed (Patton, 2002) which involves referring back to respondents in an attempt to confirm that the research has accurately represented their ideas and responses. Member checking occurred twice in this study. First, the interview transcription packages were provided to the participants and they were invited to clarify, elaborate, or suggest changes to the original responses. All the participants agreed that the transcriptions were accurate and besides correcting some spelling mistakes, none of the participants had any queries about or requested adjustments to the transcripts. The second member checking occurred after the analysis of the data was completed. Once again, all the participants were invited to respond to the interpretations and to correct inaccurate information. On this occasion, the participants did not suggest any amendments.

In the following section, a description of the coaches' teaching styles during their coaching sessions is given. The insights the coaches held about these teaching styles during coaching sessions are reported. In terms of structure, the following section will provide a description of the coaches' prevailing beliefs from the six interview questions posed to all coaches during the interviews. After this, a summary of the findings will be presented to provide a response to the research question: "What are the coaches' insights of the teaching styles they employ during coaching sessions?"

\section{RESULTS}

Interview question 1: "Could you identify or tell me what has or have been the major influences on the way you currently coach?"

This question was specifically designed to provide background information with regard to how and where the coaches learned the particular ways they coach. Of the participants, 11 coaches indicated that their experiences as a tennis student and the way they were coached significantly influenced the way they coach now. As Tegan explained:

My coach had a big influence on the way I coach now. I still learn from him now and just kind of automatically do what he does, the same activities and how to explain things. I can still remember how he coached me as a beginner, like the exact activities. I just try and use these activities because they were fun for me (Tegan).

Patrick outlined a similar experience: My coach had a huge influence. I learned for so long that I found that I just used the same methods and tennis games to coach my kids now. I enjoyed the way she coached me so I use these similar methods (Patrick). Bill and Chris, however, expressed a different point of view in regards to the way they were taught. Bill and Chris both claim that their experiences as tennis students had little influence on how they currently coach. Bill commented:

My coach was old school in terms of his coaching methods. I look around today and coaching is different. Less standing in lines, this is how I was taught. You didn't often play the game, just hit, run around and pick up balls and stand back in line. Maybe you played a tournament at the end of the term. I try and coach differently, play more games, more hits for the kids (Bill).

All coaches acknowledged the significant influence of a mentor on the way they currently coach. Each of the participants who were interviewed identified the Head Coach at the tennis club that they work as this mentor. Stephanie indicated that her mentor was the "primary influence on how I currently coach in my lessons" (Stephanie). Similarly, David attributed his coaching behaviour to the Head Coach (also his employer) at the tennis club where he coaches. David remarked: "the Head Coach at my club has definitely given me a lot of guidance. He writes the programs for us to use. These activities are good and fun for the kids" (David). No coaches in this study mentioned the impact or influence of formal accreditation coaching courses on their coaching.

Interview question 2: "After watching your three observed coaching sessions what are your thoughts with regard to the way you coached?"

Prior to conducting the interviews, each coach was requested to view three of their video-recorded 
coaching sessions. At the commencement of the interview, the researcher asked the respondents to comment on these coaching sessions with regard to the way they coached. All the coaches expressed a high degree of surprise and sometimes disbelief as to what transpired during these sessions. Each coach indicated and acknowledged an apparent lack of compatibility with regard to what they believed happened during the sessions and what actually ensued concerning the way they coached. All the coaches strongly believed that they had coached in a particular way that emphasised the following areas:

- Asking the players to respond to questions about technical and tactical skills and challenges.

- Permitting the players to primarily engage in game-play and rallying.

- Allowing the students to solve technical and tactical skills and challenges independent of the coach and not directly and prescriptively informing the players what to do or how to do it.

- Limited ball feeding.

The video-recorded observations indicated that

all coaches frequently employed ways of coaching that involved:

- Specifically and solely developing the technical skills of the players.

- Providing prescriptive information directly to the players to develop these skills.

- High frequency of ball feeding by the coach to enable players to develop their technical skills.

When asked to comment on what occurred during the three observations with regard to the way she coached, Tegan's response was common to all the interviewees:

Well, I thought my coaching methods had more questions, yeah, the video really shows you different things, doesn't it? I like to ask lots of questions in all my lessons. I really thought that I asked a lot of questions and I tried to get the students to figure things out for themselves ... I tried to ask questions and get them to discover for themselves ... it was a bit of a disaster really. When I looked at the video, I did heaps of talking. The second lesson was the same, I thought that I questioned, but I was telling them what to do. I even started feeding balls, which wasn't even on my lesson plan (Tegan)! Similarly, Stephanie stated:
It was a bit embarrassing (laughing), I wasn't doing half the stuff that I thought I was, it was like I was a different coach. I thought my lessons were all really Game-Based, but looking at the videos I did all this feeding of balls, I thought I used questions and the guided discovery method, but having watched the DVD I actually didn't ask that many questions. I didn't realise that I did as much telling either. It was both difficult and interesting to watch (Stephanie).

David also provided similar sentiments when he asserted: "I was basically very command style, after watching the videos, feeding balls and telling them what to do, I asked a few questions but much less that I thought and certainly less than I planned on my lesson plan" (David).

All the coaches remarked on the beneficial outcomes associated with viewing their coaching sessions. The coaches expressed strong agreement that the video-recorded footage provided a useful platform to review their performance and assist in developing their understanding of the coaching process. For instance, Chris commented:

I've never watched myself before, so it was really good to see what I do and how I coach, I thought that I might have used a more GameBased Approach, but I did a lot of talking, I didn't shut up actually!, one of the comments from my learning facilitator was that I spent too much time explaining things and the kids didn't get to hit enough balls, at the time I didn't really agree with her, but after watching the lesson, I can see that I spent way too much time talking (Chris).

Jimmy also found the experience beneficial and mentioned: "Well, it was good to see what I was actually doing and how the kids were responding to the activities, I also picked up quite a bit from what I was doing and how I could possibly do things better." (Jimmy). David suggested that the video-recording of sessions should feature more prominently in the accreditation courses at Tennis Australia (TA):

Yeah, I managed to take a look at the videos on Wednesday night, it was quite good, good to look at yourself, coach, and see what is happening, actually happening on the court. It would be good to have a copy of the DVD when you speak with the learning facilitator, instead of them just telling you about the lesson and 
talking you through what happened, the video lets you see it for yourself (David).

Interview question 3: "Are there any additional ways of coaching tennis?"

The interviews revealed an assortment of terms that coaches used to describe the way they coached during their video-recorded coaching sessions. These terms are listed in Table 1. All the respondents in this study reported to using a GameBased Approach (GBA) or game-based method during their three observed coaching sessions. Most of the coaches $(n=10)$ also nominated a discovery style, discovery method, modern way/method, and discovery approach as a way they coached in each of their sessions. Four of the respondents also claimed to have employed a constraints-based approach during the sessions.

Table 1. Outline of all the terms that the interviewed coaches $(n=13)$ described as the ways that they coached during their three observed coaching session

\begin{tabular}{|l|c|}
\hline \multicolumn{1}{|c|}{$\begin{array}{c}\text { Ways of coaching tennis } \\
\text { described by coaches }\end{array}$} & $\begin{array}{c}\text { Number of coaches who } \\
\text { described and coached } \\
\text { this way }\end{array}$ \\
\hline Game-Based Approach (GBA) & 13 \\
\hline Game-based method & 13 \\
\hline Discovery style & 10 \\
\hline Discovery method & 10 \\
\hline Discovery approach & 10 \\
\hline Modern way/method & 10 \\
\hline Games-centred strategy & 9 \\
\hline Games strategy & 9 \\
\hline Games approach & 9 \\
\hline Constraints-based approach & 4 \\
\hline
\end{tabular}

All the coaches remarked on the beneficial outcomes associated with viewing their coaching sessions. The coaches expressed strong agreement that the video-recorded footage provided a useful platform to review their performance and assist in developing their understanding of the coaching process. The insights of the coaches in this study suggest that for these coaches assertion that GBA's can stimulate player motivation and by extension player enjoyment and fun resonates. GBA's were seen to strongly encourage the employment of questions to stimulate players' learning. Common responses among all the coaches with regard to employing GCAs consisted of: "It's more fun" (Tegan), "It's heaps of fun" (Bill), and "It's the most fun approach" (Travis).
The coaches describing a range of terms that were often used synonymously, their definition and interpretations were remarkably similar. For example, common definitions and interpretations among the interviewed coaches of a Game-Based Approach (GBA) consisted of:

I mainly used a Game-Based Approach (GBA).

In all the lessons I tried to get the students to figure out the answers for themselves ... I asked questions and got them to discover for themselves (Jimmy).

The coach should not tell the kids what to do, but ask lots of questions and just let them figure it out and make all or most of the decisions, explore the solutions and create the answers to the activities or technical problems they are having. This is a Game-Based Approach (GBA) essentially (Tim).

The coaches also commented that encouraging players to become involved in the decision making process during coaching sessions was the most effective avenue for developing tennis players. This aspect can be seen in the following comment:

The Game-Based Approach (GBA) produces better learners, better players. They work it out for themselves and remember better. Telling kids what to do doesn't really work, won't help them on the weekend when they are playing, they get to rely on the coach too much when it's technique and or traditional. When kids work it out themselves and on their own they learn more and remember better (Tegan).

This quote also suggests that the coach provided an accurate overview and representation of employing GBA's. The following comments provided by two of the coaches capture a common thought among all the coaches:

I pretty much instruct the same way with everyone, or at least I try and do it this way ... it's my style to let kids and adults for that matter discover the skills of what to do on their own (Patrick).

I don't think coaches should have to change their style. The Game-Based Approach is just a better way to coach, so it can be done with all players. It doesn't really matter what the age of the player is, or the level really, you might have to ask easier questions to the younger kids, but, that's about it. All kinds of players find this a more fun way to learn (Bill). 
Interview question 4: "Can you interpret and define the ways you coached during your three observed coaching lessons?"

The terms Game-Based Approach (GBA), game-based method, discovery method, playing games approach, discovery style, constraints-based approach, indirect approach and modern way/ method were defined and interpreted in a similar manner among 11 (out of 13) of the coaches that employed these terms. Common interpretations and definitions among the coaches consisted of:

- Asking the players to respond to questions about technical and tactical skills and challenges.

- Permitting the players to primarily engage in game-play and rallying.

- Allowing the students to solve technical and tactical skills and challenges independent of the coach.

- Not directly and prescriptively informing the players what to do or how to do it.

Jimmy's response provides a specific example of this frequent occurrence:

I mainly used a Game-Based Approach. In all the lessons I tried to get the students to figure out the answers for themselves ... I asked questions and got them to discover for themselves. Using discovery methods or a Game-Based Approach (GBA) allows maximum participation. You shouldn't really tell the students, rather make them explore and find out on their own (Jimmy).

In the following response, it is clear to see that Andrea's definition and interpretation of the discovery method, the GBA, indirect method and modern way/method are analogous:

The discovery method is about asking heaps of questions and discovery, it's all about questioning ... it is really the modern approach to coaching tennis nowadays, the old traditional way of telling and being direct instead of using an indirect Game-Based Approach (GBA) is old fashioned really. Coaches have to let the students find out the answers. The GameBased Approach (GBA) is the same really, ask questions and let the kids explore and find out for themselves. I reckon that I used these most of the time ... if not all the time (Andrea).

All 13 coaches additionally commented on the specific role of the coach in these ways of coaching tennis. All the interviewees believed that when delivering atennis session the coach should withdraw from hitting (feeding) tennis balls to players, and not directly and prescriptively informing students on how to perform various skills. In this case, the players should commence an activity by hitting (feeding) themselves. Furthermore, it was asserted by all coaches that the primary role of the coach, in this way of coaching tennis, is to repeatedly pose questions to the learners who must make their own decisions and determine answers to technical and tactical problems. An example of this can be seen in Patrick's response:

You let kids figure it out what to do. Let them decide what to do and how to do it. You try and ask lots of questions. The coach doesn't get involved in the lesson like feeding or anything like that. Just let the kids play and discover answers for themselves (Patrick).

Table 2. Outline of the terms that the interviewed coaches $(n=13)$ used interchangeably and common examples of these definitions and interpretations

\begin{tabular}{|c|c|}
\hline $\begin{array}{l}\text { Coaching terms listed by } \\
\text { coaches that were used } \\
\text { interchangeably }\end{array}$ & $\begin{array}{l}\text { Common examples of definitions } \\
\text { and interpretations associated } \\
\text { with the terms listed by coaches }\end{array}$ \\
\hline $\begin{array}{l}\text { - } \text { Game-Based } \\
\text { - Approach (GBA> } \\
\text { - } \text { Game-based method } \\
\text { - } \text { Playing games } \\
\text { approach } \\
\text { - Discovery method } \\
\text { - } \text { Discovery style } \\
\text { - } \text { Constraints-based } \\
\text { - } \text { approach } \\
\text { - Indirect approach. }\end{array}$ & $\begin{array}{l}\text { - "Asking questions" } \\
\text { - "Pose lots of questions" } \\
\text { - "Let kids play games" } \\
\text { - "Let them make the } \\
\text { - "Lecisions" } \\
\text { - "Let them rally and explore } \\
\text { - "Allow the players to figure } \\
\text { it out" } \\
\text { - "Don't tell them how to do } \\
\text { it" } \\
\text { - "Let the players explore and } \\
\text { figure out the answers on } \\
\text { their own" } \\
\text { - "Questioning and answering } \\
\text { of challenges, rather than } \\
\text { being direct and telling" }\end{array}$ \\
\hline
\end{tabular}

Interview question 5: "Can you interpret and define any additional ways of coaching tennis?"

Terms such as technique-based approach, traditional approach, direct style, and command approach were largely used synonymously and comparably defined and interpreted by the coaches. The additional ways of coaching tennis were generally interpreted and defined by the coaches as:

- Developing the technical skills of the players.

- Providing prescriptive information directly to the players to develop these technical skills.

- Hitting tennis balls to players (feeding tennis balls) to players to enable them to develop their technical skills.

David's comment sums up coaches interpretation of the 'traditional' approach: 
The traditional method of coaching is feeding balls to players to get their technique right. Lots of repetition and lots of direction and telling the children what it is they must do. It's really all about technique-based instructions [...] getting the technique right first (David).

Table 3 provides an outline of the terms that the coaches interviewed in this study $(n=13)$ used interchangeably when asked to describe any additional ways of coaching tennis of which they were aware of. It also delineates the common definitions and interpretations associated with these terms.

Table 3. Outline of the additional terms that the interviewed coaches used interchangeably and common examples of these definitions and interpretations

\begin{tabular}{|c|c|}
\hline $\begin{array}{l}\text { Coaching terms listed by } \\
\text { coaches that were used } \\
\text { interchangeably }\end{array}$ & $\begin{array}{l}\text { Common examples of definitions } \\
\text { and interpretations associated } \\
\text { with the terms Listed by coaches }\end{array}$ \\
\hline $\begin{array}{l}\text { - Technique-based } \\
\text { approach } \\
\text { - Traditional approach } \\
\text { - Direct style } \\
\text { - Command approach }\end{array}$ & $\begin{array}{l}\text { - "Feed lots of balls" } \\
\text { - "Feeding lots of balls to the } \\
\text { - "Tlayers" } \\
\text { "The coach makes all the } \\
\text { - "Gecisions" } \\
\text { - "'Lou want exactly" } \\
\text { - of direction" } \\
\text { - "The coach does a lot of } \\
\text { - talking and telling" } \\
\text { - "Very traditional" } \\
\text { - "Old fashioned" } \\
\text { - "Perhaps outdated" } \\
\text { - "Qery direct" }\end{array}$ \\
\hline
\end{tabular}

Interview question 6: "Can you outline and discuss your reasons for adopting these ways that you coached during the three observation sessions?"

The earlier quote by Tegan for the reasons for adopting the ways she coached during her three observed coaching sessions provided a fair representation of what the coaches thought about this question. That is, a GBA produces better learners and better players because the players are placed in practice conditions where they have to be problem solvers. A majority of the coaches $(\mathrm{n}=11)$ also believed that by employing this way of coaching, the players were more motivated and had more fun during coaching sessions. Nicole strongly believed: "It's the best way but really it's the most fun for the kids, they love it, lots of action and questions, they are in control, the coach isn't directly telling them what to do" (Nicole).
Similarly, Jill noted: "Game-Based Approach (GBA) is more fun for the kids, than direct ways of coaching ... they learn better and more in this way of coaching" (Jill). All the coaches commented that the choice and employment of a particular way of coaching did not alter as a function of the age or ability of the players they coached. Each of the coaches specified that they used the same way of coaching in all of their coaching sessions, regardless of the age level or ability of their students.

Overall, the results highlighted a lack of knowledge concerning the theoretical and practical application of various teaching styles required for coaching tennis to junior players. It was also evident that the coaches lacked self-awareness with regard to their own coaching performance and were incapable of accurately describing the reasons why they implement particular ways of coaching. The interviews also revealed that coaches used an assortment of terms to identify the way they coach and that their decision to employ certain ways of coaching did not alter as a function of the age group, skill level or ability of the players they were coaching. Summary of the major findings from the interviews of the coaches are:

- A majority of the coaches $(n=11)$ nominated a mentor in addition to their experiences as a tennis student and the way they were taught as having the greatest influence on the way they currently coach;

- An assortment of terms are used by the coaches to identify the way they coach;

- All the coaches claimed to have primarily implemented a Game-Based Approach during all of their observed coaching sessions;

- Common definitions and interpretations among the interviewed coaches of a Game- Based Approach (GBA) consisted of 'asking questions of students', 'letting the students play games' and 'allowing the students to solve answers to movement challenges' and 'not feeding balls the players';

- Having fun' and the 'best way to learn' were commonly submitted as reasons for employing particular ways of coaching during sessions;

- The coaches lacked an ability to accurately describe the ways they coached during their observed coaching sessions;

- Despite the coaches' limited awareness of the ways they coach during coaching sessions, they did display an ability to articulate the type of 
learning environment they wished to produce and behaviours they wanted to encourage;

- The coaches possessed limited knowledge, however, of the reasons why these behaviours might be of benefit; and

- The coaches' decision to employ certain ways of coaching did not alter as a function of the age group, skill level or ability of the players they were coaching.

\section{DISCUSSION}

In the discussion, we refer to all the coaches who participated in as a collective group $(n=$ 13). We deemed it prudent to combine the group owing to the same interview schedule (i.e. interview questions, duration of interview) in addition to similar conclusions emanating from the participants' responses.

An analysis of the coaches' narratives indicated that observing and/or discussing aspects of coaching with a mentor as well as playing experience had a greater influence on current coaching behaviour than attending an accreditation course. These reflections were consistent with other research findings. In a review of the development of coaching as a profession, Woodman (1993) suggested that the basis of improved coaching lies with coach education and development programs. Considering that coaching accreditation is acquired following the successful completion of a formal course it might be expected that this source of learning would serve as the most important. However, there exists evidence that formal education accreditation programs are only one of a number of methods that coaches consider important in learning to coach.

To date, a number of scholars have empirically approached the critical question of how coaches learn and to what value they attribute these methods to becoming coaches (Bloom, DurandBush, Schinke \& Salmela, 1998; Bloom, Salmela \& Schinke, 1995; Cote et al., 1995; Fleurance \& Cotteaux, 1999; Gould, Giannini, Krane \& Hodge, 1990; Irwin, Hanton \& Kerwin, 2004; Jones, Armour \& Potrac, 2004; Lemyre, Trudel \& Durand-Bush, 2007; McCullick, Belcher \& Schempp, 2005; Salmela, Draper \& Desjardins, 1994; Salmela, 1995; Schinke, Bloom \& Salmela, 1995; Wright, Trudel \& Culver, 2007). While there is some disparity among these studies as to the perceived level of importance of formal coach accreditation programs, there is agreement that other learning experiences perform a substantial role in the acquisition of knowledge. These alternative experiences include: playing experience, mentoring, discussions with other coaches, observation and professional experience.

The responses to interview question 1: "Could you identify or tell me what has or have been the major influences on the way you currently coach?" showed no coaches in this study mentioning the impact or influence of the formal accreditation coaching courses on their coaching presents potentially important ramifications for continuing professional development. In hindsight, it would have been useful to explore whether the participants recognised they were copying a coaching mentor or role model, and upon reflection did this person use a direct or GBA. While the coaches were using the language of GBA evident in coaching documents to describe their practice, as a majority of the coaches identified a mentor as exercising the greatest degree of influence on the way that they coached tennis, it is incumbent upon coach education providers to explore avenues that may provide a more profound impact on the coaches' instructional processes during accreditation courses. Furthermore, education initiatives involving the mentors of course participants may also prove beneficial. This might consist of information pertaining to the benefits of implementing a variety of teaching styles in addition to a greater awareness of the theoretical assumptions that underpin these practices.

The findings also revealed that coaches in his study utilised a variety of terms to describe the way that they coached, and that many of these terms were used interchangeably. The responses recorded by the coaches shared similarities with other research. According to Bailey and Macfadyen (2007) teaching models, strategies, approaches, methods, styles, practices and formats are terms that have been employed interchangeably in educational literature. Similarly, Ashworth (1998) has reported that classroom teaching-learning procedures have been directed by the following terms including: teaching models, strategies, styles, methods, behaviours, techniques and practices. In a review of the literature that clarified the specific definitions and distinct purposes of these terms, Ashworth (1998) found that these terms are:

- Common, frequently used, and often interchanged in our professional literature.

- Not in competition, but rather used as synonyms. 
- Used to offer recommendations about how to structure the teaching/learning interaction ( $\mathrm{p}$. $119)$.

The study by Ashworth also revealed that "the data did not support any consistent or precise definition for these individual terms; rather the definitions of these teaching options (methods, styles, strategies, etc.) were arbitrary and personalised according to each author's usage" (p. 119). Correspondingly, many tennis coaching accreditation manuals use terms interchangeably when referring to particular instructional practices. Coach education accreditation manuals from the International Tennis Federation (ITF) and Tennis Australia (TA) describe teaching styles (command, direct, indirect and discovery) and coaching approaches (traditional, technique-centred, gamecentred, game-based, integrated, situational, complex, total, holistic, constraints-based and modern) (Crespo \& Reid, 2009; Tennis Australia, 2010a, 2010b). Furthermore, some scholars have asserted:

In tennis, the conceptualisation of different coaching approaches or philosophies has been confounded by disparate terminology and coaching parlance. This has led to a certain ambiguity in global tennis coaches' education and exacerbated the extent to which the instruction of the game is anecdotally based (Reid et al., 2007, p. 1).

What appears to be lacking in these publications is a framework of common terminology that clearly defines specific ways that are available for tennis coaches to coach during coaching sessions. In the absence of consistency in terminology, "reliable communication, accurate implementation, and assessment of ideas are difficult if not impossible" (Mosston \& Ashworth, 2008, p. 3). Moreover, the inconsistent use and understanding of terminology creates confusion and leads to the misinterpretation of events that ultimately limits educational practice (Mosston \& Ashworth, 2008). It could be asserted that the anecdotal declarations by some researchers in connection to tennis coaches using "disparate terminology and coaching parlance" (Reid et al., 2007 , p. 1) have been empirically supported in this study. In spite of the coaches describing a range of terms that were often used synonymously, their definition and interpretations were remarkably similar. The coaches interpretations a GBA align with many of the recommended practices associated with indirect instruction. The implementation of questions requires a player to implement different levels of thought processes to respond and is considered a beneficial coaching behaviour that promotes a player's active learning through problem solving, discovery, and an awareness of performance (Chambers \& Vickers, 2006). As indicated earlier, a noticeable discrepancy was realised between the self-identified use of teaching styles and what was evident during the observations.

The findings of this study demonstrated that all the coaches who were observed provided highly prescriptive and direct instruction during their observed coaching sessions. In spite of this, all the coaches during the interviews stated that they believed that they created a learning environment that encouraged players to make decisions and respond to questions about technical and tactical skills and challenges.

Beyond mentioning that these types of instructional processes were the most effective when conducting coaching sessions, the coaches were unable to explain why this was so. This situation was perhaps similar to what Light (2008) calls an epistemological gap, or cognitive dissonance. This is evident when practitioners utilise the language of particular instructional guidelines or ways of coaching, but persist in coaching in an alternative way owing to a lack of understanding (Davis \& Sumara, 2003; Light, 2008).

Similar to previous research (Partington \& Cushion, 2011; Smoll \& Smith, 2006), the results of the interviews suggested that coaches were incapable of accurately describing their individual coaching behaviours. This strongly indicated that the coaches exhibited a reduced self-awareness of their coaching in practice. This point was further demonstrated when the coaches were requested to provide feedback and commentary after viewing their video-recorded coaching sessions prior to the interview. All the coaches expressed a high degree of surprise and disbelief as to what transpired during these coaching sessions. Each coach indicated and acknowledged an apparent lack of compatibility about what they believed had happened during the sessions and what actually ensued with regard to the way that they coached. As indicated in the Results, all the coaches strongly believed that they had coached in a particular way that emphasised elements that could be ascribed to a GBA.

Motivation and engagement were cited by the coaches as the reason for use of GBA. In connection 
with learning in the affective domain (i.e., emotion, fun, enjoyment) Oslin and Mitchell (2006), found that GBAs were considered to be more enjoyable, and learners reported elevated levels of motivation when participating in Physical Education lessons (Griffin, Oslin \& Mitchell, 1995). Similarly, research conducted by Light (2003) and Light and Georgakis (2005) suggested that a GBA produced increased enjoyment and empowerment, greater engagement and improved physical activity levels in learners. Research that has explored games learning in connection to the affective domain have provided support for the claims that GCAs can be more engaging and motivating than doing drills (Jarrett \& Harvey 2014).

The results from the interviews in this study revealed, however, that the coaches believed that a GBA, consisting of high levels of indirect instruction, is the most effective way to coach tennis. This might indicate that the coaches assumed importance and benefits of this type of instructional processes in developing practice engagement. Although research has been conducted into the adeptness of GBAs compared with a techniquecentred approaches, or as Kirk (2010) described a sport as sport techniques approach, evidence of the authority of one or the other concerning the development of motor skill acquisition is equivocal (Oslin \& Mitchell, 2006).

Throughout the course of the interviews, all coaches commented that the choice and employment of a particular way of coaching did not alter as a function of the age or ability of the players whom they coached. Each of the coaches specified that they used the same way of coaching in all of their observed coaching sessions regardless of the age level or ability of their players. Furthermore, nearly all the coaches stated that they did not believe that they should be required to change the way they coach. The six Club Professional (CP) coaches, who primarily instructed players of an intermediate level between the ages of 6 and 8 years, stated that they employed the same way of coaching regardless of the age or ability of the player. The responses from the seven Junior Development (JD) coaches who spent most time coaching players of a beginner level aged between 4 and 5 years indicated similar thoughts.

These beliefs are in stark contrast to literature concerning the use of various teaching styles (Byra, 2006; Rink, 2001; Rukavina \& Foxworth, 2009; Whipp, Taggart, \& Jackson, 2012). A common conception among these authors stipulates that coaches should cater and respond to the needs of all learners, with consideration being provided to the player's developmental readiness, interest, and competence. Mawer (1995) suggests that "as no one method covers all eventualities, the effective teacher will have the ability to switch, mix, and blend teaching strategies to suit his objectives and pupil responses" (p. 228). Rink (2001) expressed similar pedagogical sentiments to Mosston and Ashworth (2008) in that "there may not be a best way to teach, but there may be a best way to teach particular content to particular learners" (p. 123).

\section{CONCLUSION}

While the sample of coaches interviewed for this stage of the study limited its capacity for generalisation to all tennis coaches it does provide worthwhile information with regard to the insights into the teaching styles that coaches employ during coaching sessions. It also offers support for the claim by Bowes \& (2006) that coaching is a complex process that has been oversimplified in the coaching literature and in coach development programs. More specifically, it highlights that coaches in this study lacked knowledge concerning the theoretical and practical application of various teaching styles required for coaching. It additionally revealed that coaches lacked self-awareness and an understanding in relation to their own coaching performance.

The points discussed here have implications for curriculum initiatives in coach education as well as for future professional development opportunities. The learner guides used in the accreditation coaching courses in Australia recommend that tennis coaches should combine the use of direct and discovery teaching styles with the latter nominated as the preferred teaching style (Tennis Australia; 2010a, 2010b). The predominant use of technique orientated coaching is not necessarily compatible with the favoured teaching processes identified in these publications. The necessity for coaches to understand and purposefully implement a range of teaching styles to achieve various learning outcomes is paramount. As no one teaching style encompasses all learning eventualities, an effective coach must possess the capability to change and combine teaching styles during sessions. Furthermore, GBA like the Australian developed Game Sense approach are not 'game only' pedagogical models and include the necessary use of a multiplicity of teaching styles as dictated by the task objective 
within the generalised GBA coaching structure of game-reflect and practice-game. However, if tennis coaches are to understand their behaviours and if they are to value the limitations and possibilities associated with these behaviours they must firstly know what they are doing. The finding from this study is that the personally anticipated coaching behaviour of the coach was not what they realised upon observation of their coaching, which was thought to be game-based but was largely technique centred and directive command and practice style coaching.

Lyle and Cushion (2010) have described coaching research as neglecting to characterise satisfactorily the practice of coaching and as failing to impact on coach education. Coaches are often confronted with nebulous challenges and their practice is repeatedly exposed to elevated levels of variability and ambiguity. Sport pedagogy specialists have argued that the constrictions of practice may be specific to a particular context or common to all coaches, however, our current understanding of what they do and why they do it is largely limited (Lyle \& Cushion, 2010; Mallett, 2005; Saury \& Durand, 1998). Therefore, research that considers "what coaches do and why they do it, still offers much in developing our understanding about coaching" (Cushion, 2010, p. 44).

\section{REFERENCES}

Ashworth, S. (1998, July 5-8). Defining and implementing teaching style. Paper presented at the AIESEP World Sport Science Congress on Education for Life, Jyvaskyla, Finland.

Australian Sports Commission. (1996). Game sense: Perceptions and actions - research report. Belconnen, ACT: Australian Sports Commission.

Australian Sports Commission. (2015). Playing for life resources. Retrieved from https://sportingschools.gov. au/resources-and-pd/schools/playing-for-life-resources

Bailey, R., \& Macfadyen, T. (Eds). (2007). Teaching physical education 5-11. London: Continuum.

Berg, K., \& Latin, R. (2004). Essentials of research methods in health, physical education, exercise science, and recreation. London: Lippincott Williams and Wilkins.

Bloom, G. A., Durand-Bush, N., Schinke, R. J., \& Salmela, J. H. (1998). The importance of mentoring in the development of coaches and athletes. International Journal of Psychology, 29, 267-289.

Bloom, G. A., Salmela, J. H., \& Schinke, R. J. (1995). Expert coaches' views on the training of developing coaches. In R. Vanfraecham-Raway \& Y. V. Auweele (Eds.), Proceedings of the Ninth European Congress on Sport (pp. 401-408). Brussels: Free University of Brussels.

Bowes, I., \& Jones, R. L. (2006). Working at the edge of chaos: Understanding coaching as a complex, interpersonal system. The Sport Psychologist, 20, 235245.

Brandl-Bredenbeck, H. P., \& Kampfe, A. (2012). Surveys. In K. Armour \& D. Macdonald (Eds.), research Methods in Physical Education and Youth Sport (pp. 174-188). New York, NY: Routledge.

Breed, R., \& Spittle, M. (2011). Developing game sense through tactical learning: A resource for teachers and coaches. Melbourne: Cambridge University Press.
Byra, M. (2006). Teaching styles and inclusive pedagogies. In D. Kirk, D. Macdonald \& M. O’Sullivan (Eds.), The handbook of physical education (pp. 449446). London: Sage.

Chambers, K., \& Vickers, J. N. (2006). Effects of bandwidth feedback and questioning on the performance of competitive swimmers. Sport Psychology, 20(2), 184-197.

Cote, J., Salmela, J. H., Trudel, P., Baria, A., \& Russell, S. (1995). The coaching model: A grounded assessment of expert gymnastic coaches' knowledge. Journal of Sport and Exercise Psychology, 17, 1-17.

Crespo, M., \& Reid, M. (2009). Coaching beginner and intermediate tennis players. Spain: International Tennis Federation (ITF).

Creswell, J. W., \& Plano Clark, V. L. (2011). Designing and conducting mixed methods research (2nd ed.). Los Angeles: Sage.

Cushion, C. J. (2010). Coach Behaviour. In J. Lyle \& C. Cushion (Eds.), Sports coaching: Professionalism and practice (pp. 43-61). London: Churchill Livingstone, Elsevier.

Davis, B., \& Sumara, D. (2003). Why aren't they getting this? Working through the regressive myths of constructivist pedagogy. Teaching Education, 14, 123140. doi: 10.1080/1047621032000092922

Fleurance, P., \& Cotteaux, V. (1999). Development of expertise in elite athletic coaches in France. Avante, 5(2), 54-68.

Freebody, P. (2003). Qualitative research in education: Interaction and practice. London: Sage.

Gilbert, W., \& Trudel, P. (2004). Analysis of coaching science research published from 1970-2001. Research Quarterly for Exercise and Sport, 75, 388-399. doi: 10.1080/02701367.2004.10609172

Gould, D., Gianinni, J., Krane, V., \& Hodges, K. (1990). Educational needs of elite U.S. national Pan American 
and Olympic coaches Journal of Teaching in Physical Education, 9, 322-344.

Griffin, L., Oslin, J., \& Mitchell, S. (1995). An analysis of two instructional approaches to teaching net games. Research Quarterly for Exercise and Sport, 66, (Suppl. 1), A64.

Jarrett, K., \& Harvey, S. (2014). Recent trends in research literature on games-based approaches to teaching and coaching games. In R. Light, J. Quay, S. Harvey \& A. Mooney (Eds.), Contemporary developments in games teaching (87-102). New York, NY: Routledge.

Harvey, S., Cushion, C., \& Massa-Gonzalez, A. N. (2010). Learning a new method: Teaching games for understanding in the coaches' eyes. Physical Education and Sport Pedagogy, 15(4), 361-382. doi: http://dx.doi. org/10.1080/17408980903535818

Irwin, G., Hanton, S., \& Kerwin, D. (2004). Reflective practice and the origins of elite coaching knowledge. Reflective Practice, 5, 425-442. doi: 10.1080/14623940600688423

Jones, R. L., Armour, K., \& Potrac, P. (2004). Sports coaching cultures: From practice to theory. London: Routledge.

Jones, R. L. (2006). The sports coach as educator: Reconceptualising sports coaching. London: Routledge.

Keeves, J. P., \& Sowden, S. (1997). Analysis of descriptive data. In J. P. Keeves (Ed.), Educational research methodology and measurement: An international handbook. (2nd ed.) (pp. 296-306). Oxford, UK: Pergamon.

Kirk, D. (2010). Physical education futures. New York, NY: Routledge.

Lemyre, F., Trudel, P., Durand-Bush, N. (2007). How youth sport coaches learn to coach. The Sports Psychologist, 21, 191-209.

Light, R. (2008). Complex learning theory: Its epistemology and its assumptions about learning: Implications for physical education. Journal of Teaching in Physical Education, 27, 439-453.

Light, R., \& Georgakis, S. (2005). Integrating theory and practice in Teacher Education: The impact of a games sense unit on female pre-service primary teachers' attitudes towards teaching physical education. Journal of Teaching in Physical Education New Zealand, 38(1), 67-83.

Light, R. (2003). Preservice teachers' responses to TGfU in an Australian University: No room for heroes. In J. Butler, L. Griffin, B. Lombardo \& R. Nastasi (Eds.), Teaching games for understanding in physical education and sport: An international perspective (pp. 67-78). Oxon Hill, MD: AAHPERD Publications.

Lyle, J., \& Cushion, C. (Eds.). (2010). Sports coaching: Professionalisation and practice. Edinburgh: Churchill Livingston Elsevier.

Lyle, J. (2002). Sports coaching concepts: A framework for coaches' behaviour. New York, NY: Routledge.
Mallett, C. (2005). How do you coach? Sports Coach, 28(2), 3-10.

Mawer, M. (1995). The effective teaching of physical education. London: Longman.

McCullick, B. A., Belcher, D., \& Schempp, P. G. (2005). What works in coaching and sport instructor certification programs? The participants' view. Physical Education and Sport Pedagogy, 10(2), 121-137.

Mosston, M., \& Ashworth, S. (2008). Teaching physical education. (1st ed.). Online: Spectrum Institute for Teaching and Learning. Retrieved from http://www. spectrumofteachingstyles.org/e-book-download.php

Oslin, J., \& Mitchell, S. (2006). Game-centred approaches to teaching physical education. In D. Kirk, D. Macdonald \& M. O'Sullivan (Eds.), The handbook of physical education (pp. 627-651). London: Sage.

Partington, M., \& Cushion, C. (2011). An investigation of the practice activities and coaching behaviors of professional top-level youth soccer coaches. Scandinavian Journal of Medicine \& Science in Sports, 13(2), 1-9. doi: 10.1111/j.1600-0838.2011.01383.x

Patton, M. Q. (2002). Qualitative evaluation and research methods (3rd ed.). Newbury Park, CA: Sage.

Potrac, P., Jones, R., \& Armour, K. (2002). It's all about getting respect: The coaching behaviours of an expert English soccer coach. Sport, Education and Society, 7(2), 183-202. doi: 10.1080/1357332022000018869

Potrac, P., Jones, R., \& Cushion, C. (2007). Understanding power and the coach's role in professional English soccer: A preliminary investigation of coach behaviour. Soccer and Society, 8(1), 33-49. doi: 10.1080/14660970600989509

Reid, M., Crespo, M., Lay, B., \& Berry, J. (2007). Skill acquisition in tennis: Research and current practice. Journal of Science and Medicine in Sport, 10, 1-10. doi: http://dx.doi.org/10.1016/j.jsams.2006.05.011

Reitman-Olson, J. S., \& Biolsi, K. (1991). Techniques for representing expert knowledge. In K. A. Ericsson \& J. Smith (Eds.), Studies for expertise: Prospects and limits (pp. 240-285). Cambridge, MA: Cambridge University Press.

Rink, J. E. (2001). Investigating the assumptions of pedagogy. Journal of Teaching in Physical Education, 20, 112-128.

Rukavina, P. B., \& Foxworth, K. R. (2009). Using motorlearning theory to design more effective instruction. Journal of Physical Education, Recreation and Dance, 80(3), 17-37.

Salmela, J. H., Draper, S. P., \& Desjardins, G. (1994). Transitional phases of experts of ice and field hockey coaches' careers. Access to Active Living, 570-575.

Salmela, J. H. (1995). Learning from the development of expert coaches. Coaching and Sport Sciences Journal, 2(2), 3-13.

Saury, J., \& Durand, M. (1998). Practical knowledge in expert coaches: On-site study of coaching in sailing. 
Research Quarterly in Exercise and Sport, 69(3), 254266.

Schinke, R. J., Bloom, G. A., \& Salmela, J. H. (1995). The career stages of elite Canadian basketball coaches. Avante, 1(1), 48-62.

Smith, M., \& Cushion, C. (2006). An investigation of the in-game behaviours of professional, top-level youth soccer coaches. Journal of Sports Sciences, 24(4), 355366.

Smoll, F. L., \& Smith, R. E. (2006). Development and implementation of a coach training program: cognitive behavioural principles and techniques. In J. M. Williams (Ed.), Applied sport psychology: Personal growth to peak performance (5th ed.) (pp. 458-480). New York, NY: McGraw-Hill.
Tennis Australia. (2010a). Junior development coaching course learner guide. Melbourne: Tennis Australia.

Tennis Australia. (2010b). Club professional coaching course learner guide. Melbourne: Tennis Australia.

Tesch, R. (1990). Qualitative research: Analysis types and software tools. Bedford, UK.

Whipp, P., Taggart, A., \& Jackson, B. (2012). Differentiation in outcome-focused physical education: Pedagogical rhetoric and reality. Physical Education and Sport Pedagogy, 7(12), 1-11.

Woodman, L. (1993). Coaching: A science, and art, an emerging profession. Sport Science Review, 2(2), 1-13.

Wright, T., Trudel, P., \& Culver, D. (2007). Learning how to coach: The different learning situations reported by youth ice hockey coaches. Physical Education and Sport Pedagogy, 12(2), 127-144.
Corresponding author Shane Pill

School of Education

Flinders University

Sturt Road, Bedford Park 5042, Adelaide South Australia

Email shane.pill@flinders.edu.au 